Indústria e Desenvolvimento Econômico:

desafios e perspectivas

18 a 20 de setembro de 2018

Uberlândia - Minas Gerais

\title{
O papel e as contribuições da indústria de venture capital no Brasil
}

\author{
Solange Gomes Leonel \\ Centro Universitário de Belo Horizonte - UNIBH
}

\section{RESUMO}

Este artigo discute o papel da indústria brasileira de venture capital (VC) no financiamento de empresas nascentes e emergentes de base tecnológica. O principal objetivo é reunir elementos que possibilitem avaliar se essa indústria poderia contribuir para o desenvolvimento tecnológico brasileiro. Para tal, a pesquisa está estruturada em três partes. Primeiro, aborda-se a trajetória institucional da indústria de VC no Brasil. Segundo, explora-se o perfil dos investimentos realizados por 13 organizações de VC atuantes no Brasil entre 1999 e 2013. Terceiro, discute-se o papel dos programas públicos brasileiros de VC, CRIATEC e INOVAR, no financiamento da inovação. Os resultados obtidos indicam que a indústria de VC brasileira demonstra ter um baixo apetite para o risco, apostando em empresas com trajetórias tecnológicas bem definidas ou produtos que são cópias de modelos de negócios bem-sucedidos em outros países. A conclusão que se chega é que ela tem um papel secundário no financiamento do desenvolvimento tecnológico que o Brasil precisa para realizar o tão almejado catching up.

PALAVRAS-CHAVE: Venture Capital; Inovação; Política Governamental

\section{ABSTRACT}

This paper discusses the role of venture capital (VC) firms in the financing of innovative small and mediumsized enterprises within the Brazilian economy. The paper's primary goal is to bring together elements that help to understand whether VC firms could be part of a catching up friendly financial system to help Brazil in its quest for technological catching up. The research is structured into three parts: i) a review of the institutional trajectory of Brazilian VC industry; ii) a detailed analysis of the investments made by $13 \mathrm{VC}$ firms between 1999 and 2013; and ii) a discussion on the role played by two public Brazilian VC programs, CRIATEC e INOVAR. The results indicate that the Brazilian VC industry has a low appetite for risk. By and large, it invests in firms from sectors with technology trajectories known or copycats from established and successful business models. The conclusion is that the VC firms play only a minor role in funding new opportunities for the Brazilian technological dynamism

KEYWORDS: Venture Capital, Financing of Innovation, Government Policy

Área 3 - Estratégias empresariais, financiamento e governança corporativa

JEL: G24, O31, O38 


\section{Introdução}

O temo venture capital (VC) é multifacetado. De forma ampla, trata-se de recurso financeiro - proveniente de poupança individual ou lucro retido por corporações - disponível para investimento em empreendimentos com alto potencial de lucratividade, mas que envolvam um certo grau de risco. Nota-se, entretanto, uma certa tendência de muitos autores e formuladores de políticas públicas de usar o termo VC para se referir, ao mesmo tempo, ao mecanismo geral para financiar novas empresas, especialmente aquelas baseadas em tecnologia, e a estrutura particular do que atualmente é reconhecido como uma organização de VC.

Neste artigo, o foco são as organizações de VC. Essas são descritas aqui como organizações financeiras profissionais especializadas no aporte de capital, por meio da compra de uma participação acionária, em empresas nascentes e emergentes não cotadas em bolsas de valores. Na literatura econômica, essas organizações são frequentemente citadas como uma das principais fontes de capital externo capaz de mitigar os problemas relacionados ao financiamento de inovação como, por exemplo, assimetria de informação e alto grau de incerteza (cf. Sahlman, 1990; Black e Gilson, 1998; Gompers e Lerner, 2001; Metrick e Yasuda, 2010). Por outro lado, alguns pesquisadores têm se posicionado mais criticamente sobre as reais contribuições dessas organizações no financiamento da inovação (cf. Zider 1988; Mulcahy, 2013) ou alertado sobre a forte dependência da indústria de VC de sua base institucional e a dificuldade de se reproduzi-la fora de seu país de origem, os Estados Unidos (cf. Chesnais e Sauviat, 2005; Chesnais, 2006).

No Brasil, a indústria de VC é relativamente nova. Ela começou a ser delineada juntamente com a atividade de PE na década de 1970 para financiar a base pesada da industrialização brasileira. Desde o início de sua trajetória, essa indústria vem contando com o apoio institucional e financeiro do Banco Nacional de Desenvolvimento Econômico e Social (BNDES) e da Financiadora de Estudos e Projetos (FINEP).

Observa-se, porém, que apesar de todos os esforços empreendidos pelo setor público para promover a indústria local de VC, ainda não está claro o que ela é capaz de oferecer ou o quão funcional ela é para financiar o desenvolvimento tecnológico brasileiro. Os dados disponíveis apontam que atualmente falta disposição dessa indústria para assumir os riscos do financiamento à inovação. Isso pode ser notado: i) nos investimentos feitos em empreendimentos com trajetórias tecnológicas bem definidas ou que são cópias de modelos bem-sucedidos em outros países; ii) no baixo número de organizações de VC dedicadas ao financiamento de empresas nascentes e emergentes de base tecnológica; e iii) no ativismo do setor público implementando programas públicos de $\mathrm{VC}$ e aportando capital em fundos gerenciados pelo setor privado.

Nessa direção, este artigo tem como objetivo discutir o papel e as contribuições das organizações de VC para a modernização tecnológica da indústria brasileira. Para tal, ele está estruturado em seis seções, incluindo esta introdução. A segunda seção apresenta notas metodológicas sobre os dados utilizados. $\mathrm{Na}$ terceira, aborda-se a trajetória institucional da indústria de VC no Brasil. A quarta explora o perfil dos investimentos realizados por 13 organizações de VC atuantes no país entre 1999 e 2013 . A quinta seção discute os resultados dos programas públicos de VC, CRIATEC e INOVAR, implementados pelo BNDES e pela FINEP, respectivamente. Por fim, a sexta seção conclui o artigo.

\section{Notas metodológicas}

$\mathrm{Na}$ literatura econômica, o VC é descrito como um tipo especial de private equity (PE). Em uma típica negociação de PE, um investidor compra as ações de uma empresa com a expectativa de alavancar o seu desenvolvimento para, então, vendê-la (KAPLAN; STRÖMBERG, 2008, METRICK; YASUDA, 2010). Como o VC é uma subcategoria de PE, os termos VC e PE são muitas vezes usados como sinônimos. Essa confusão é acentuada pelas similaridades encontradas nas negociações realizadas tanto pelas organizações de VC quanto pelas organizações especializadas em aquisições alavancadas - também chamadas de 
organizações de PE. Em geral, elas utilizam os mesmos contratos legais, lidam com a mesma terminologia financeira, possuem a mesma base de clientes e buscam realizar os lucros com a venda da empresa ou a oferta pública de ações (da sigla em inglês IPO). A grande diferença é o foco do negócio.

O foco das organizações de PE são as empresas maduras de diversos setores industriais que já comercializam produtos e possuem receita recorrente (WOOD; WRIGHT, 2009). A estratégia dessas organizações é investir em empresas com baixo desempenho financeiro ou com risco de falência, torná-las lucrativas para, então, vendê-las (KAPLAN; STRÖMBERG, 2008). Por sua vez, as organizações de VC tendem a focar em novos empreendimentos de setores mais intensivos em conhecimento, com amplo mercado consumidor e grande potencial de crescimento (METRICK; YASUDA, 2010).

Apesar do foco distinto, grande parte dos dados disponíveis sobre a indústria de VC no Brasil tendem a ser agregados aos dados da atividade de PE. Essa dificuldade é vista tanto no censo mais completo já feito sobre as atividades de PE/VC no Brasil, o $2^{\circ}$ Censo brasileiro da indústria de private equity $e$ venture capital publicado pela Agência Brasileira de Desenvolvimento Industrial (ABDI), quanto nos relatórios de consolidação das atividades de PE/VC publicados anualmente pela Associação Brasileira de Private Equity e Venture Capital (ABVCAP) em parceria com a empresa de consultoria KPMG.

A imprecisão do escopo dos dados disponíveis e a forte aproximação entre as operações de VC e PE limitam a tentativa de traçar os eventos que abordam apenas a trajetória institucional da indústria de VC no país. Assim, a seção 3 apresenta dados e informações que permeiam tanto a evolução da indústria de VC quanto da indústria de PE no Brasil.

$\mathrm{Na}$ quarta seção, os dados utilizados foram coletados a partir das bases de dados da ABVCAP e Preqin - empresa de pesquisa especializada em ativos como PE, VC, fundos de hedge e bens imóveis - e de informações públicas disponíveis nos websites das organizações de VC e de suas empresas investidas. Como a base de dados da Preqin é reconhecidamente uma das mais atualizadas e completas sobre as operações da indústria mundial de investimentos, acredita-se que os dados utilizados na seção 4 forneçam uma boa noção sobre os investimentos realizados pelas organizações de VC no Brasil.

$\mathrm{Na}$ quinta seção, os dados utilizados foram coletados a partir de diferentes fontes. Para analisar o CRIATEC, recorreu-se aos dados públicos disponibilizados pelas gestoras dos três fundos da série CRIATEC: Antera, Bozano Investimentos e Inseed. Como o foco do CRIATEC é financiar empresas nascentes e emergentes de base tecnológica, as informações utilizadas são exclusivas das operações de VC. Já os dados do programa INOVAR foram coletados a partir da base dados da FINEP. Cabe destacar que esses dados não refletem apenas as operações de PE. Mas diferentemente do que se observa na seção 3, aqui os limites entre as operações de PE e VC estão mais claros. A única exceção cabe ao Gráfico 2. Nesse gráfico, as empresas investidas estão distribuídas por setor sem distinção entre as operações de VC e PE.

\section{A trajetória institucional da indústria de venture capital no Brasil}

A década de 1970 é considerada um marco para a indústria de VC brasileira. Nesse período, os setores público e privado iniciaram uma série de investimentos na aquisição de ações de empresas com alto potencial de rentabilidade e crescimento. Segundo Gorgulho (1996) e Pavani (2003), o interesse do Estado na promoção desse tipo de investimento no país estava ligada à viabilização de projetos do II PND (Plano Nacional de Desenvolvimento), lançado no final de 1974 pelo governo Geisel, que buscavam estimular a produção nacional de bens de capital, insumos básicos e energia. O financiamento estatal pode ser explicado pelo fato de que os bancos privados estavam relativamente distantes do "processo de industrialização, limitando-se ao crédito comercial de curto prazo para capital de giro, sem oferecer créditos longos e relevantes para os investimentos de grande escala" (COUTINHO, 1999, p. 361).

Nessa direção, o BNDES lançou em 1974 três subsidiárias para prover capital e participar temporariamente das empresas investidas, a saber: i) Insumos Básicos S.A. (FIBASE), destinada a capitalizar as empresas produtoras de insumos básicos (química, petroquímica, metalurgia etc); ii) Mecânica Brasileira S.A. (EMBRAMEC), voltada para o fortalecimento do capital das empresas do setor 
de bens de capital; e iii) Investimentos Brasileiros S.A (IBRASA) que tinha como objetivo investir em empresas privadas dos demais setores produtivos (NAJBERG, 1989).

Gorgulho (1996) afirma que dentre as três subsidiárias, a IBRASA "foi a que mais se aproximou das características de capital de risco, apresentando uma disposição explícita de participar temporariamente das empresas investidas e promovendo uma maior expansão do mercado de capitais" (GORGULHO, p. 132). Souza Neto e Stal (1991) destacam, entretanto, que grande parte dos investimentos realizados pelas três subsidiárias foi direcionado para as grandes empresas estabelecidas e não para as novas e pequenas e médias empresas (PMEs). Eles ainda ponderam que as políticas implementadas tinham como objetivo "absorção e redução de custos industriais e transferência de tecnologia a partir do mundo desenvolvido, do que redução dos riscos de novos e pequenos empreendimentos com características inovadoras" (SOUZA NETO; STAL, p. 41).

Em 1982, por medida de racionalidade administrativa, o BNDES eliminou essa segmentação setorial com a unificação das três subsidiárias em torno de uma nova empresa denominada BNDES participações S.A (BNDESPAR) (NAJBERG, 1989). Assim como as subsidiárias anteriores, o BNDESPAR seguia a política de participação minoritária no capital das empresas, temporalidade do investimento e incentivo à captação de recursos no mercado.

Por sua vez, a FINEP lançou em 1976 o programa ADTEN (Apoio ao Desenvolvimento Tecnológico da Empresa Nacional) que possibilitou investimentos nas empresas sob a forma de participação no risco por meio de ações, debêntures etc (MELO, 2009). Segundo Souza Neto e Stal (1991, p. 41), com o ADTEN, a FINEP “[...] formalizou o emprego do capital de risco no fomento tecnológico no Brasil". Ele também abriu espaço para novos programas implementados pela FINEP pare estimular a indústria de VC nas décadas seguintes. De acordo com Pavani (2003), por conta da carteira deficitária, o programa foi descontinuado em 1991.

Do lado da iniciativa privada, Pavani (2003) afirma que várias empresas começaram a atuar como organizações de PE no Brasil em meados dos anos 1970. É difícil precisar quantas organizações de PE existiam naquele período, pois muitas empresas foram criadas como holdings sem tratamentos fiscais e contábeis diferenciados. Dentre essas, a BrasilPar criada em 1976 por meio de uma parceria entre o Unibanco e o Banco Paribas é considerada uma das primeiras organizações de PE no Brasil. A partir de 1980, a empresa sofreu uma restruturação operacional e foi capitalizada por grupos brasileiros e internacionais, dentre os quais estavam as empresas Pão de Açúcar, Multibrás, Villares e IFC/Banco Mundial. Além da atividade original de PE, a empresa passou a oferecer o serviço de assessoria em finanças corporativas. Em 1996, a BrasilPar vendeu a gestão de recursos de PE e focou na atividade de assessoria financeira ${ }^{1}$.

Outra iniciativa do setor privado que merece destaque é a criação da CRP Companhia de Participações. A CRP foi criada em 1981 por um grupo com mais de 150 empresas privadas, formando a Participações Rio-grandenses S/A (PARGS) e pelos bancos públicos Badesul (Banco de Desenvolvimento do Rio Grande do Sul) e BRDE (Banco Regional de Desenvolvimento do Extremo Sul). O objetivo era apoiar o crescimento de empreendedores na região sul do país. ${ }^{2}$ A CRP é considerada a mais antiga empresa de capital de risco atuante no Brasil (PAVANI, 2003).

É importante destacar que ao final da década de 1970, o Brasil havia concluído o ciclo de industrialização e acumulado ao longo de trinta anos uma taxa média anual do PIB de 6,5\% (COUTINHO, 1999). No entanto, não havia sido criada uma hegemonia do capital nacional sobre o sistema industrial. O desenvolvimento tecnológico, oriundo de setores manufatureiros mais sofisticados e de maior valor agregado, permanecia nas mãos das empresas estrangeiras.

No início dos anos 1980, o desenvolvimento da indústria de PE/VC sofreu com a perda de dinamismo da economia (PAVANI, 2003). O clima desfavorável foi agravado pela "crise da dívida", entre

\footnotetext{
${ }^{1}$ Disponível em: <http://www.brasilpar.com.br/historico.asp >. Acesso em 17/05/2017.

${ }^{2}$ Disponível em: <http://www.crp.com.br/historico>. Acesso em 17/05/2017.
} 
1981 e 1983, que "marginalizou o país do mercado financeiro internacional, segregando a economia brasileira do mercado financeiro mundial até o início dos anos 90" (COUTINHO, 1999, p. 364). Além disso, o país também sofreu com o acelerado processo de inovação tecnológica nos países centrais. O Brasil não foi capaz, por exemplo, de fomentar estratégias de desenvolvimento para acomodar o novo complexo de indústrias de produtos eletrônicos que crescia mundialmente. Embora tivesse um mercado interno potencialmente grande, o Brasil se viu refém de sua política de desenvolvimento orientada para dentro e estrutura produtiva heterogênea. Esta defasagem do setor industrial deixou o país de fora do processo inicial de integração da economia mundial com a formação de blocos comerciais regionais e globalização financeira (RODRÍGUEZ, 2009).

Esse cenário econômico desfavorável teve impactos na disponibilidade de recursos do setor público para a indústria de VC. De acordo com Souza Neto e Stal (1991), o Banco Central, atendendo a uma recomendação do Conselho Monetário Nacional, reduziu consideravelmente a concessão de créditos subsidiados por órgãos públicos por meio das resoluções $n^{0} 827$ e 834 publicadas em 1983. Nas palavras de Souza Neto e Stal (1991, p. 42), "mesmo não atingindo a modalidade de capital de risco, o instrumento limitou esse tipo de financiamento a menos de uma dúzia de casos".

Além do cenário econômico desfavorável, a falta de mecanismos regulatórios e fiscais adequados também representavam um entrave para o desenvolvimento da indústria de VC no país. Somente em 1986, através do Decreto-Lei 2.287, regulado pelas resoluções $\mathrm{n}^{\circ}$ 1.184/86 e 1.346/87, as sociedades de capital de risco (SCRs) foram institucionalizadas e passaram a receber isenções e incentivos fiscais (GORGULHO, 1996). O objetivo social das SCRs era única e exclusivamente a aquisição de participações minoritárias e transitórias em PMEs. Apesar do avanço nos marcos regulatórios, Gorgulho (1996) ressalta que: i) a regulamentação das SCRs limitava os investimentos ao capital próprio das SCRs, excluindo a realização de empréstimos ou a utilização de instrumentos de dívida, e ii) a regulamentação do BACEN sobre ganhos de capital inviabilizava o desenvolvimento das SCRs.

No início da década de 1990, o cenário seguiu desfavorável para a indústria de VC. O Brasil vivenciava um período de agravamento da crise financeira e cambial, herdada de períodos anteriores. Ao mesmo tempo, uma grave recessão econômica se abateu sobre as principais economias mundiais. Para atrair os investidores ávidos por formas alternativas de remunerar o capital com taxas de retorno mais atrativas, o governo do então presidente Fernando Collor, por meio dos planos Collor I e II, "iniciou o processo de liberalização e desregulamentação financeira que permitiu atrair montantes consideráveis de capital financeiro especulativo internacional" (TAVARES, 1999). O governo também adotou várias medidas como a redução e eliminação dos controles quantitativos e administrativos sobre as importações - para promover a abertura da economia à concorrência externa.

Do lado das políticas públicas, o BNDES lançou em 1991 o Programa de Capitalização de Empresas de Base Tecnológica (CONTEC), um condomínio sem personalidade jurídica e de natureza escritural, sob administração do BNDESPAR (GORGULHO, 1996). O objetivo do CONTEC era estimular o desenvolvimento tecnológico no país e apoiar as PMEs de base tecnológica. De acordo com Pavani (2003), o CONTEC investiu em várias empresas nascentes e emergentes. Ele também destinou recursos para duas organizações de PE/VC: CRP e Pernambuco Participações S.A.

Já do lado regulatório, o Estado, por meio da Comissão de Valores Mobiliares (CVM), lançou em 1994 a Instrução 209 que regulamentava os investimentos em PMEs, com a criação do Fundo de Investimentos em Empresas Emergentes (FMIEE). O FMIEE tem prazo máximo de 10 (dez) anos e deve ser direcionado para empresas emergentes com patrimônio líquido consolidado de até R\$ 60 milhões.

A partir de 1994, com a estabilidade econômica e o controle inflacionário, o Brasil começou a atrair mais investidores. Como resultado, novas organizações de PE começaram a atuar no país. Em 1994, a recém-criada GP Investimentos conseguiu levantar um fundo de PE, o GPCP I, de US\$ 500 milhões. Em 1997, ela conseguiu levantar um segundo fundo, o GPCP II, de US\$ 800 milhões. Nesse mesmo ano, foi criado o primeiro fundo bilionário de PE no Brasil, o CVC/Opportunity, uma parceria entre o Citibank 
Venture Capital (CVC) e o Opportunity, com foco nas privatizações do governo do então presidente Fernando Henrique Cardoso (ABDI, 2011, p. 62).

As crises financeiras que se abateram ao redor do mundo entre 1997 e 1998 tornaram os investidores, especialmente os estrangeiros, mais avessos ao risco. De acordo com Ribeiro (2005), o resultado foi uma diminuição na entrada de novas organizações de PE/VC no Brasil. Já no início de 1999, a desvalorização do real frente ao dólar - com a adoção do regime de câmbio flutuante - e a euforia do mercado mundial com as empresas do setor de tecnologia da informação e comunicação (TIC) incentivaram a entrada de recursos estrangeiros para investimentos em fundos de PE/VC locais (RIBEIRO; ALMEIDA, 2005). Carvalho, Ribeiro e Furtado (2006) afirmam que a evolução do capital comprometido ${ }^{3}$ em operações de PE/VC no Brasil aumentou significativamente entre 1999 e 2000, passando de US\$ 3,71 bilhões para US\$ 4,95 bilhões. Seguindo essa tendência, 13 novas organizações de PE/VC iniciaram as atividades no país em 2000 (RIBEIRO, 2005).

Em 1999, a FIR Capital começou as suas operações de PE/VC. Entre os seus casos de sucesso, consta os investimentos em duas empresas brasileiras pioneiras em suas áreas de conhecimento, são elas: Biobrás, adquirida pela empresa Novo Nordisk A/S em 2001, e Akwan, adquirida pela empresa Google em 2005. Em 2007, a Draper Fisher Jurvetson (DFJ) - empresa de VC norte-americana com presença em quatro continentes - adquiriu uma participação acionária na FIR Capital, sinalizando o crescente interesse das empresas de VC estrangeiras pelo mercado brasileiro (LEONEL, 2014, p. 147).

Em meio ao colapso no mercado financeiro mundial, desencadeado pela "bolha da Internet", houve uma queda nos investimentos feitos pelas organizações de PE/VC entre 2000 e 2002. Segundo Pavani (2003), foram realizadas 87 operações de PE/VC em 2000 contra 34 em 2002 e os investimentos caíram de US\$ 1,4 bilhões em 2000 para US\$ 164 milhões em 2002.

Na contramão desse cenário desfavorável, a FINEP lançou em maio de 2000 o programa INOVAR, fruto de uma cooperação técnica firmada junto ao Fundo Multilateral de Investimentos do Banco Interamericano de Desenvolvimento (BID/Fumin). De acordo com a FINEP (2001), o programa INOVAR foi concebido como um conjunto de inciativas para promover o desenvolvimento e a consolidação da indústria de $\mathrm{VC}$ no Brasil e o desenvolvimento de empresas de base tecnológica. Como parte dos esforços, também foram lançados o Venture Forum, uma agenda permanente de rodadas de negócios, e a Incubadora de Fundos Inovar, uma estrutura voltada para estimular a criação de fundos de VC para as empresas nascentes e emergentes brasileiras.

Do lado regulatório, em 2003, a CVM publicou a instrução 391 que regulamentava os Fundos de Investimento em Participações (FIPs). De acordo com Carvalho, Ribeiro e Furtado (2006), as novas regras deram maior flexibilidade à atividade de $\mathrm{PE} / \mathrm{VC}$ no país, pois possibilitaram que as organizações de $\mathrm{PE} / \mathrm{VC}$ recebessem investimentos de fundos de pensão e investidores estrangeiros. Adicionalmente, a lei 11.312/2006 reduziu a zero a alíquota de imposto de renda sobre os ganhos auferidos pelos investidores dos fundos de PE/VC.

A partir de 2005, observa-se o surgimento de novas organizações de VC locais dedicadas exclusivamente ao aporte de capital em empresas nascentes como, por exemplo, a Monashees Capital, Antera Gestão de Recursos S.A e Confrapar. Nessa mesma linha, o BNDES implementou em 2007 o programa CRIATEC para capitalizar e prover apoio gerencial para micro e pequenas empresas inovadora. O fundo CRIATEC I de R 100 milhões contou com aportes feitos pelo BNDESPAR e pelo Banco do Nordeste do Brasil S/A (BNB). Ainda em 2007, a FINEP iniciou o Seed Forum, segmentação do Venture Forum, voltado para empresas nascentes, micro e de pequeno porte que buscam investimentos para estruturação e/ou crescimento inicial do negócio.

\footnotetext{
${ }^{3}$ Refere-se ao montante pré-definido contratualmente de aporte de capital dos investidores nos fundos de PE/VC. Esse capital é efetivamente desembolsado à medida que os fundos de PE/VC fazem as chamadas de capital para investimento nos ativos (empresas).
} 
Já a partir de 2010, observa-se um aumento do interesse de organizações de VC estrangeiras pelo Brasil com o início das operações da Burrill \& Company, focada nos segmentos de biotecnologia e ciências da vida. Em 2011, a Accel Partners e Redpoint também começaram a operar no Brasil, mas sem a criação de fundos locais. Essa é, aliás, uma tendência seguida por várias organizações estrangeiras. Em geral, essas organizações têm optado por utilizar suas estruturas já constituídas em outras localidades como, por exemplo, as Ilhas Cayman. Segundo estudo do MIT (2013, p. 22), as Ilhas Cayman oferecem acesso a um tipo de sistema jurídico e flexibilidade tributária não encontrados no Brasil. Esse estudo ainda afirma que existe um consenso entre os investidores de que os veículos de investimento utilizados no país são muito morosos e geralmente mais caros que as estruturas offshore. Cabe destacar que a opção por offshore também é praticada em outros mercados, inclusive nos EUA.

Em 2013, a FINEP lançou o programa INOVA 4 que representa uma tentativa do governo federal de promover a elevação da produtividade na economia, tendo os investimentos do tipo VC como uma de suas vertentes. Por sua vez, o BNDES lançou em 2013 e 2016 mais dois fundos: o CRIATEC II ${ }^{5}$, com um capital comprometido de $\mathrm{R} \$ 186$ milhões, e o CRIATEC III $^{6}$, com um capital comprometido de $\mathrm{R} \$ 200$ milhões, respectivamente.

Já o ano de 2016 é marcado por uma mudança no arcabouço regulatório da indústria de PE/VC com a publicação da CVM 578, substituindo instruções anteriores como, por exemplo, a CVM 209 e 391 . A nova instrução modernizou e flexibilizou as regras que regem a constituição, funcionamento e administração dos fundos de PE/VC. Entre outros pontos, a CVM passou a autorizar que os fundos constituídos no Brasil invistam em ativos no exterior.

Cabe destacar que apesar de todos os esforços do setor público e iniciativas privadas para promover a indústria de $\mathrm{VC}$ discutidos ao longo desta seção, o percentual de recursos direcionados para investimentos em empresas nascentes e emergentes no Brasil ainda é muito baixo. Segundo dados da KPMG (2016, p.12), do total de capital comprometido em 2015, US\$ 37,91 bilhões $(96,5 \%)$ correspondem as operações de PE e US\$ 1,37 bilhões (3,5\%) as operações de VC. Comparativamente, nos EUA, principal mercado de PE/VC no mundo, do total de US\$ 144,5 bilhões de capital comprometido em 2015, US\$ 116,3 bilhões (80,5\%) correspondem as operações de PE e US\$28,22 bilhões (19,5\%) as operações de VC (NVCA, 2016, p. 23). Quanto à distribuição dos investimentos por setor, os dados discutidos na seção a seguir apontam que grande parte dos investimentos feitos pela indústria de VC foram direcionados para o setor de TIC (inclui tecnologias das áreas de microeletrônica, telecomunicações e informática), especialmente em empresas que são cópias de modelos de negócios bem-sucedidos em economias centrais.

\section{O perfil de investimento da indústria de venture capital no Brasil}

Para entender as reais contribuições da indústria de VC para o financiamento da inovação, mapeou-se os investimentos feitos pelas principais organizações de VC atuantes no país entre 1999 e 2013. Essas organizações foram identificadas a partir da base de dados de membros associados da ABVCAP. Foram selecionados os membros que têm como foco investimentos em empresas nascentes e emergentes.

Inicialmente, foram identificadas 24 organizações na base de dados da ABVCAP. Posteriormente, essa base foi confrontada com a base de dados da Preqin para eliminar possíveis inconsistências. Desse confronto, a amostra inicial reduziu para 13 organizações de VC. Como a Preqin possui uma base de dados mais robusta e completa que a base da ABVCAP, acredita-se que essas 13 organizações representem, possivelmente, grande parte da atividade de VC realizada no Brasil no período estudado.

\footnotetext{
4 Disponível em: < http://www.finep.gov.br/apoio-e-financiamento-externa/programas-e-linhas/programas-inova/o-que-e-oprograma-inova>. Acesso em 17/05/2017.

${ }^{5}$ Disponível em: < http://www.criatec2.com.br/institucional/ >. Acesso em 17/05/2017.

${ }^{6}$ Disponível em: < http://www.inseedinvestimentos.com.br/criatec3/>. Acesso em 17/05/2017.
} 
Da amostra final, foi possível identificar o perfil de 52 investimentos realizados em 45 empresas nascentes e emergentes (Quadro 1). A diferença entre o número de investimentos e empresas investidas pode ser explicada pelo fato de que uma mesma empresa recebeu investimentos de diferentes organizações de VC.

Em relação às indústrias apoiadas, observa-se que dos 52 investimentos realizados, 48 se enquadram na indústria de TIC, três em Biotecnologia e um em Nanotecnologia. Esses dados apontam que existe uma clara tendência das organizações de $\mathrm{VC}$ atuantes no Brasil de alocar recursos para as empresas nascentes e emergentes na área de TIC.

Além da preferência por indústrias que possuem trajetórias tecnológicas bem definidas, observa-se que também existe uma tendência dessas organizações de investir em negócios que são "cópias" de modelos de negócios bem-sucedidos em outros países. ${ }^{7}$ Essa estratégia adotada pelas organizações de VC locais é conhecida como tropicalização. O objetivo é reduzir os riscos inerentes aos investimentos em empresas nascentes em mercados emergentes. De acordo com especialistas, no Brasil 70\% das empresas nascentes nos setores de Internet e telefonia móvel que são investidas por organizações de VC estrangeiras são clones de outras empresas. ${ }^{8}$

Outra informação relevante extraída do Quadro 1 é o tipo de produtos/serviços que as empresas investidas desenvolvem. No setor de TIC, há um predomínio de empresas que exploram a prestação de serviço como, por exemplo, o serviço de comércio eletrônico ou a distribuição online de conteúdo eletrônico.

Quanto às rodadas de investimento, os dados disponíveis mostram que pelo menos 17 investimentos foram do tipo Series A, 11 foram Series Seed, cinco foram Series B e um Séries $C .{ }^{9}$ Isso indica que boa parte das rodadas de investimentos foram direcionadas para auxiliar as empresas a desenvolver o conceito do produto (Series Seed) e escalar os produtos e/ou expandir mercados (Series A). Quanto ao volume de recursos investidos por essas organizações, os poucos dados disponíveis sinalizam que foram investidos mais de US\$ 150 milhões, entre 1999 e 2013, em empresas nascentes e emergentes do setor de TIC. Entretanto, acredita-se que esse número tenha sido bem superior.

Para finalizar, cabe destacar a atual situação das 45 empresas citadas no Quadro 1. Consultas nas bases de dados da Preqin e nos websites das organizações de VC e suas empresas investidas indicam que 22 empresas ainda permanecem em carteira e 14 já foram desinvestidas ${ }^{10}$. Do total de empresas desinvestidas, 13 foram vendidas para outras empresas e uma foi contabilizada como perda (write-off) pelo fundo. Nenhuma delas havia aberto capital na BM\&FBOVESPA até maio de $2017 .{ }^{11}$ Isso indica que apesar de a modalidade de saída via IPO oferecer maiores retornos financeiros ${ }^{12}$, o mercado acionário brasileiro ainda não consegue estimular os desinvestimentos via abertura de capital. Para as nove empresas restantes não há informações públicas disponíveis.

\footnotetext{
${ }^{7}$ As empresas Baby.com, Elo7, Kekanto e Peixe Urbano são clones das empresas norte-americanas Diapers.com, Etsy, Yelp e Groupon, respectivamente.

${ }^{8}$ Disponível em: < http://www.economist.com/node/21556269>. Acesso em: 17/05/2017.

${ }^{9}$ Os investimentos feitos pelas organizações de VC são geralmente divididos em rodadas (ou Series). Cada rodada possui objetivos específicos que correspondem ao estágio de desenvolvimento de cada empresa investida.

${ }^{10}$ As empresas que já foram desinvestidas são Baby.com, Bolsa de Mulher, Buscatrip Ciashop, Comum IP, Cyberlynxx Excegen, Hands, NetMovieShoes4you, Peixe Urbano, Softcorp Spring Wireless e Startupi.

11 Disponível em:< http://www.bmfbovespa.com.br/pt br/produtos/listados-a-vista-e-derivativos/renda-variavel/empresaslistadas.htm>. Acesso em 17/05/2017.

${ }^{12}$ Segundo Leeds e Sunderland (2003, p. 115), a saída via IPO oferece maiores retornos às organizações de VC do que a venda para um investidor privado - em média, os IPOs rendem 60 por cento ao ano contra 15 por cento ao ano quando a saída é realizada via venda para outro investidor.
} 


\section{QUADRO 1}

Perfil de Investimento de 13 organizações de PE/VC: 1999-2013

\begin{tabular}{|c|c|c|c|c|c|c|}
\hline Organização & Empresa Investida & $\begin{array}{c}\text { Ano de } \\
\text { Fundação }\end{array}$ & $\begin{array}{c}\text { Ano de } \\
\text { Investimento }\end{array}$ & $\begin{array}{c}\text { Tipo de } \\
\text { Investimento }\end{array}$ & Produtos e/ou serviços & Setor/Indústria \\
\hline \multirow[t]{4}{*}{ Accel Partners } & Baby.com.br & $\mathrm{NI}^{1}$ & 2012 & Series B & e-Commerce & TIC \\
\hline & Kekanto & NI & 2011 & Series A & Rede social/Plataforma de Comunicação & TIC \\
\hline & Elo7 & 2008 & 2011 & Series A & e-Commerce & TIC \\
\hline & Shoes4you & NI & 2011 & Series A & e-Commerce & TIC \\
\hline Mountain do Brasil & Veduca & NI & 2012 & NI & Plataforma de e-learning & TIC \\
\hline (Bolt Ventures) & Startupi & 2008 & 2013 & Seed & Portal de informações sobre startups & TIC \\
\hline \multirow[t]{9}{*}{ Confrapar } & Starline Tecnologia & NI & $2011 / 2013$ & NI / Series B & Plataforma de e-learning & TIC \\
\hline & S/A & & & & & \\
\hline & Izzui & NI & 2013 & NI & Plataforma de e-learning & TIC \\
\hline & Fisgo & 2010 & 2012 & Series A & Site de classificados & TIC \\
\hline & Oktagon Games & $\mathrm{NI}$ & 2012 & NI & Jogos digitais & TIC \\
\hline & Canal do Crédito & 2009 & $2011 / 2012$ & Series A / Series & Plataforma de serviços financeiros & TIC \\
\hline & & & & $\mathrm{B}$ & & \\
\hline & ePrimeCare & 2005 & 2010 & NI & Helthcare & TIC \\
\hline & Via6 & 2006 & 2006 & Series A & Rede social/Plataforma de comunicação & TIC \\
\hline \multirow[t]{2}{*}{ El Area } & Buscatrip.com & NI & 2007 & NI & Ferramenta de busca & TIC \\
\hline & Descomplica & 2011 & 2012 & Series A & Plataforma de e-learning & TIC \\
\hline
\end{tabular}


(Continuação)

\begin{tabular}{|c|c|c|c|c|c|c|}
\hline Organização & Empresa Investida & $\begin{array}{c}\text { Ano de } \\
\text { Fundação }\end{array}$ & $\begin{array}{c}\text { Ano de } \\
\text { Investimento }\end{array}$ & $\begin{array}{c}\text { Tipo de } \\
\text { Investimento }\end{array}$ & Produtos e/ou serviços & Setor/Indústria \\
\hline & Samba Ads & NI & 2013 & Seed & Plataforma de vídeo streaming & TIC \\
\hline e.Bricks Digital & Startupi & 2008 & 2013 & Seed & $\begin{array}{c}\text { Portal de informações sobre } \\
\text { startups }\end{array}$ & TIC \\
\hline \multirow[t]{2}{*}{ Intel Capital } & Web Radar & NI & 2013 & NI & $\begin{array}{l}\text { Big Data Analytics e Internet das } \\
\text { Coisas }\end{array}$ & TIC \\
\hline & Geofusion & NI & 2013 & NI & Software de geomarketing & TIC \\
\hline \multirow[t]{8}{*}{ Ideiasnet } & Zura! & NI & 2008 & Seed & e-Commerce & TIC \\
\hline & Spring Wireless & 2001 & 2008 & Series C & Plataforma de aplicações móveis & $\mathrm{TIC}$ \\
\hline & NetMovies & NI & 2004 & NI & Streaming de video online & TIC \\
\hline & Softcorp & NI & $1999 / 2003$ & NI & Soluções na área de $\mathrm{TI}^{2}$ & TIC \\
\hline & Ciashop & $\mathrm{NI}$ & 2000 & Series A & Ferramentas para e-Commerce & TIC \\
\hline & Hands & NI & 2000 & Series A & Mobile advertising & TIC \\
\hline & Bolsa de Mulher & NI & 2000 & Series A & e-Commerce & TIC \\
\hline & Group & & & & & \\
\hline \multirow[t]{3}{*}{ Redpoint } & Grupo Xangô SA & 2010 & 2011 & Series A & Serviços para Internet & TIC \\
\hline & 55social.com & NI & 2012 & Series B & $\begin{array}{c}\text { Rede social/Plataforma de } \\
\text { comunicação }\end{array}$ & $\mathrm{TIC}$ \\
\hline & Shoes4you & NI & 2011 & Series A & e-Commerce & $\mathrm{TIC}$ \\
\hline Gera Venture & Rota dos Concursos & 2005 & 2013 & NI & Plataforma de e-learning & TIC \\
\hline
\end{tabular}


(Continuação)

\begin{tabular}{|c|c|c|c|c|c|c|}
\hline Organização & Empresa Investida & $\begin{array}{c}\text { Ano de } \\
\text { Fundação }\end{array}$ & $\begin{array}{c}\text { Ano de } \\
\text { Investimento }\end{array}$ & $\begin{array}{c}\text { Tipo de } \\
\text { Investimento }\end{array}$ & Produtos e/ou serviços & Setor/Indústria \\
\hline \multirow[t]{6}{*}{ Fir Capital } & ClicBusiness Software & NI & 2012 & NI & e-Commerce & TIC \\
\hline & Axado & NI & 2012 & Seed & e-Commerce & TIC \\
\hline & Myreks & NI & 2011 & Seed & $\begin{array}{l}\text { Rede social/Plataforma } \\
\text { de comunicação }\end{array}$ & TIC \\
\hline & Cyberlynxx & 2002 & 2010 & NI & Suporte Técnico/ & TIC \\
\hline & & & & & Manutenção em TI & \\
\hline & Samba Tech & NI & 2008 & Series A & $\begin{array}{l}\text { Plataforma de vídeo } \\
\text { streaming }\end{array}$ & TIC \\
\hline \multirow[t]{2}{*}{ e.ventures } & 55social.com & NI & 2012 & Series B & $\begin{array}{l}\text { Rede social/Plataforma } \\
\text { de comunicação }\end{array}$ & TIC \\
\hline & Startupi & 2008 & 2013 & Seed & e-Commerce & TIC \\
\hline \multirow[t]{6}{*}{$\begin{array}{l}\text { Jardim Botânico } \\
\text { Investimentos }\end{array}$} & Comun Ip & 2001 & 2005 & NI & $\begin{array}{c}\text { Soluções para } \\
\text { transmissão multimídia }\end{array}$ & TIC \\
\hline & Excegen & $\mathrm{NI}$ & 2005 & $\mathrm{NI}$ & Genética bovina & Biotecnologia \\
\hline & Nanox Tecnologia S.A. & NI & 2006 & NI & $\begin{array}{c}\text { Nanopartículas/ } \\
\text { Materias } \\
\text { nanoestruturados }\end{array}$ & Nanotecnologia \\
\hline & Trymed & 2004 & 2007 & NI & Pesquisas clínicas & Biotecnologia \\
\hline & Geociclo & $\mathrm{NI}$ & 2007 & NI & Fertilizantes & Biotecnologia \\
\hline & Sensedia & NI & 2007 & NI & Arquitetura de TI & TIC \\
\hline
\end{tabular}


(Continuação)

\begin{tabular}{|c|c|c|c|c|c|c|}
\hline Organização & Empresa Investida & $\begin{array}{c}\text { Ano de } \\
\text { Fundação }\end{array}$ & $\begin{array}{c}\text { Ano de } \\
\text { Investimento }\end{array}$ & $\begin{array}{c}\text { Tipo de } \\
\text { Investimento }\end{array}$ & Produtos e/ou serviços & Setor/Indústria \\
\hline \multirow[t]{11}{*}{ Monashees Capital } & GetNinjas & 2005 & $2011 / 2013$ & Seed/Series A & $\begin{array}{l}\text { Plataforma online de } \\
\text { contratação de serviços }\end{array}$ & TIC \\
\hline & & & & & Plataforma SaaS para & TIC \\
\hline & Runrun.it & NI & 2012 & Seed & $\begin{array}{c}\text { gerenciamento de } \\
\text { projetos }\end{array}$ & \\
\hline & eduK & NI & 2011 & Seed & $\begin{array}{l}\text { Plataforma de e- } \\
\text { learning }\end{array}$ & TIC \\
\hline & Rota dos Concursos & 2005 & 2011 & NI & $\begin{array}{l}\text { Plataforma de e- } \\
\text { learning }\end{array}$ & TIC \\
\hline & & & & & Software de gestão & TIC \\
\hline & Conta Azul & 2011 & 2011 & Seed & $\begin{array}{c}\text { online para pequenas } \\
\text { empresas }\end{array}$ & \\
\hline & Elo7 & 2008 & 2011 & Series A & e-Commerce & TIC \\
\hline & Oppa Design Ltda & 2011 & $2011 / 2012$ & NI & e-Commerce & $\mathrm{TIC}$ \\
\hline & Peixe Urbano & 2010 & 2012 & Series A & $\begin{array}{c}\text { e-Commerce de ofertas } \\
\text { locais }\end{array}$ & TIC \\
\hline & Baby.com.br & NI & 2011 & Series A & e-Commerce & TIC \\
\hline
\end{tabular}

1. NI = Não informado

2. TI = Tecnologia da Informação.

Fonte: Elaborado pela autora a partir da base de dados da Preqin, ABVCAP, website das organizações de VC e empresas investidas 


\section{Os fundos CRIATEC e INOVAR}

Segundo Etzkowitz (2005), naquelas sociedades onde o Estado assume um papel bastante intervencionista, os fundos públicos de VC são bastante comuns. Nesses casos, existe pouca diferenciação na divisão de papéis entre os VCs púbico e privado em termos de estágios de financiamento que cada um será mais atuante. Conforme visto na seção 3, o governo brasileiro vem se posicionando como um dos principais financiadores da indústria de PE/VC no Brasil. Para entender a relevância desse protagonismo, discute-se a seguir alguns resultados obtidos com os fundos CRIATEC e INOVAR.

O primeiro fundo da série CRIATEC - o CRIATEC I - encerrou o processo de seleção de investimentos em 2011. O fundo gerido pelo consórcio formado pela Antera Gestão de Recursos e Instituto Inovação tinha como política de investimentos apoiar empresas e/ou negócios inovadores que possuíam faturamento líquido de, no máximo, $\mathrm{R} \$ 6$ milhões no ano imediatamente anterior à capitalização do fundo. O CRIATEC $\mathrm{I}^{13}$ investiu em 36 empresas. Desse total, 16 já foram desinvestidas. Nenhuma delas realizou IPO.

Além do CRIATEC I, a série CRIATEC tem mais dois fundos em operação com foco em empresas nos setores de TIC, Biotecnologia, Agronegócios, Novos Materiais e Nanotecnologia, são eles: CRIATEC II $^{14}$, gerido pela Bozano Investimentos em parceria com a Triaxis Capital, e CRIATEC III ${ }^{15}$, gerido pela Inseed investimentos. O CRIATEC II já investiu em 22 empresas com faturamento de até R \$ 10 milhões no ano anterior ao investimento. Quanto ao CRIATEC III, uma única empresa havia sido investida até abril 2017.

O Gráfico 1 apresenta o perfil das 59 empresas apoiadas até agora pelo CRIATEC. Como as informações disponíveis sobre os setores investidos pelos fundos não são uniformes, buscou-se uma padronização a partir das tecnologias utilizadas pelas empresas investidas.

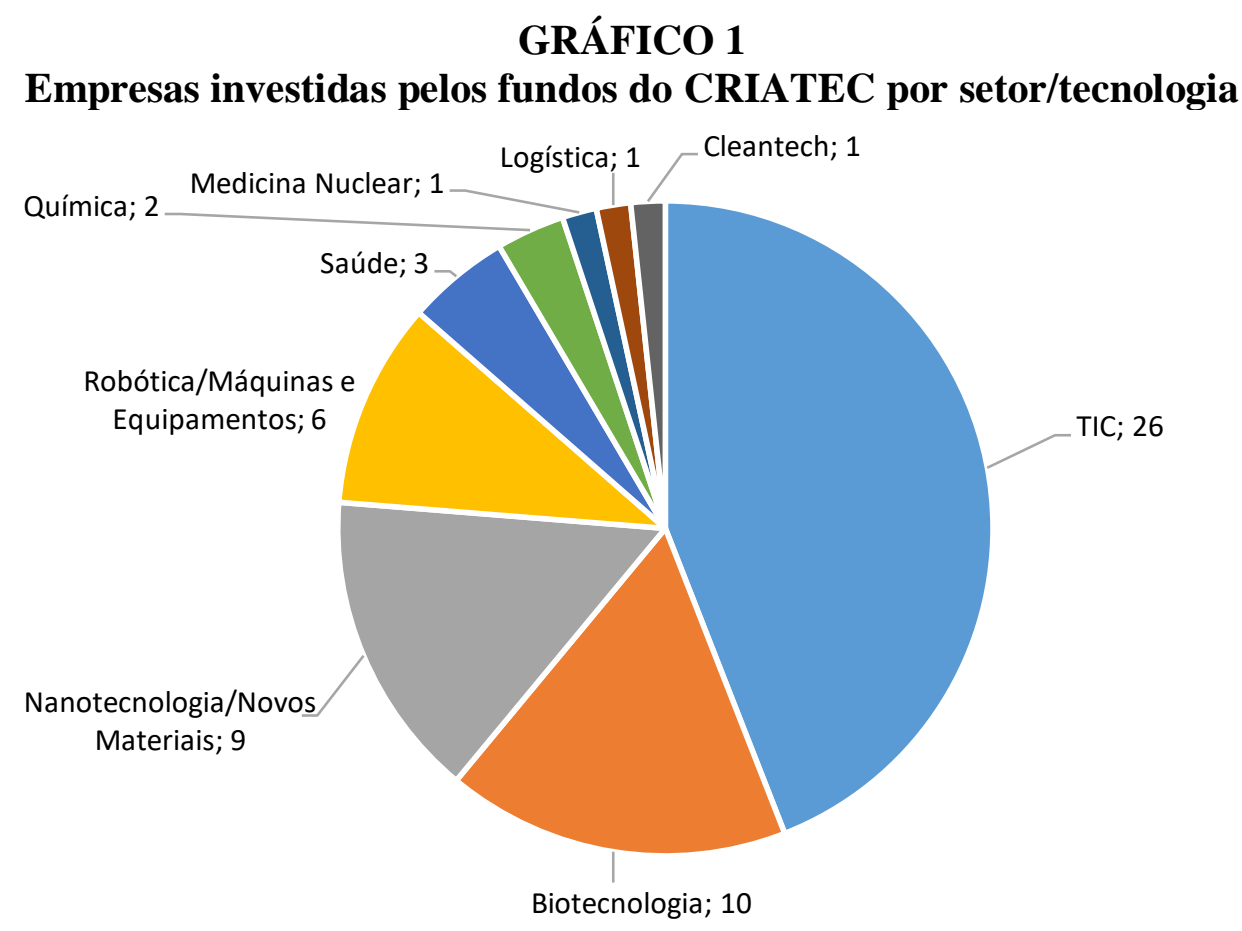

Fonte: Elaborado pela autora a partir de informações divulgadas pelos Fundo Criatec, Criatec II e Inseed.

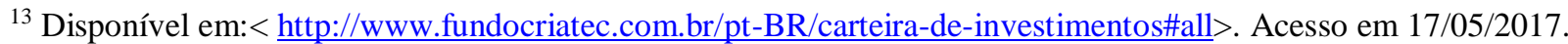

${ }^{14}$ Disponível em:< http://www.criatec2.com.br/portfolio/>. Acesso em 17/05/2017.

${ }^{15}$ Disponível em:< http://www.inseedinvestimentos.com.br/criatec3/>. Acesso em 17/05/2017.
} 
Conforme pode ser visto no Quadro 1, o principal setor investido foi TIC (26), seguindo a mesma tendência observada na seção 4 . A diferença é que enquanto na seção 4 o foco da maioria das empresas era nos serviços TIC. No CRIATEC, há uma predileção por empresas que desenvolvem sistemas compostos por hardware (eletrônica) e software (instruções), mesclando atividades indústria e de prestação de serviços. Outra diferença observada, é que nos investimentos feitos pelo CRIATEC há uma diversificação maior por tipo de setor/tecnologia. Além da TIC, os setores que mais atraíram investimentos foram Biotecnologia (10), Nanotecnologia/ Novos Materiais (9) e Robótica/Máquinas e Equipamentos (6).

Com relação ao programa INOVAR, a FINEP possui 29 fundos em operação e dois fundos já encerrados. Segundo dados divulgados pela FINEP, já foi investido aproximadamente R\$ 600 milhões nos fundos do INOVAR, sendo que parte desse recurso já beneficiou 146 empresas, das quais 127 são PMEs e 19 grandes empresas ${ }^{16}$.

Dos 29 fundos em operação, seis são do segmento PE, oito são do segmento capital semente e 15 são do segmento VC. Apesar de grande parte dos fundos ter perfil multissetorial, verifica-se uma certa predominância do segmento de TIC. As tecnologias ligadas a TIC aparecem como foco de 18 dos 23 fundos dedicados ao capital semente e VC.

Dentre o perfil das 146 empresas investidas, 71 são microempresas com faturamento de até $\mathrm{R}$ \$ 3,6 milhões, 31 são pequenas empresas com faturamento entre $\mathrm{R} \$ 3,6$ milhões e $\mathrm{R} \$ 16$ milhões, 25 são médias empresas com faturamento entre $\mathrm{R} \$ 16$ milhões e $\mathrm{R} \$ 90$ milhões, 10 são média-grandes empresas com faturamento entre $\mathrm{R} \$ 90$ milhões e $\mathrm{R} \$ 300$ milhões, e 9 são grandes empresa com faturamento acima de $\mathrm{R} \$ 300$ milhões.

Quanto ao setor das empresas investidas pelos fundos do INOVAR, o Gráfico 2 aponta a clara preferência pelo setor de Informática/Eletrônica.

\section{GRÁFICO 2 \\ Empresas investidas pelos fundos do INOVAR por setor/tecnologia}

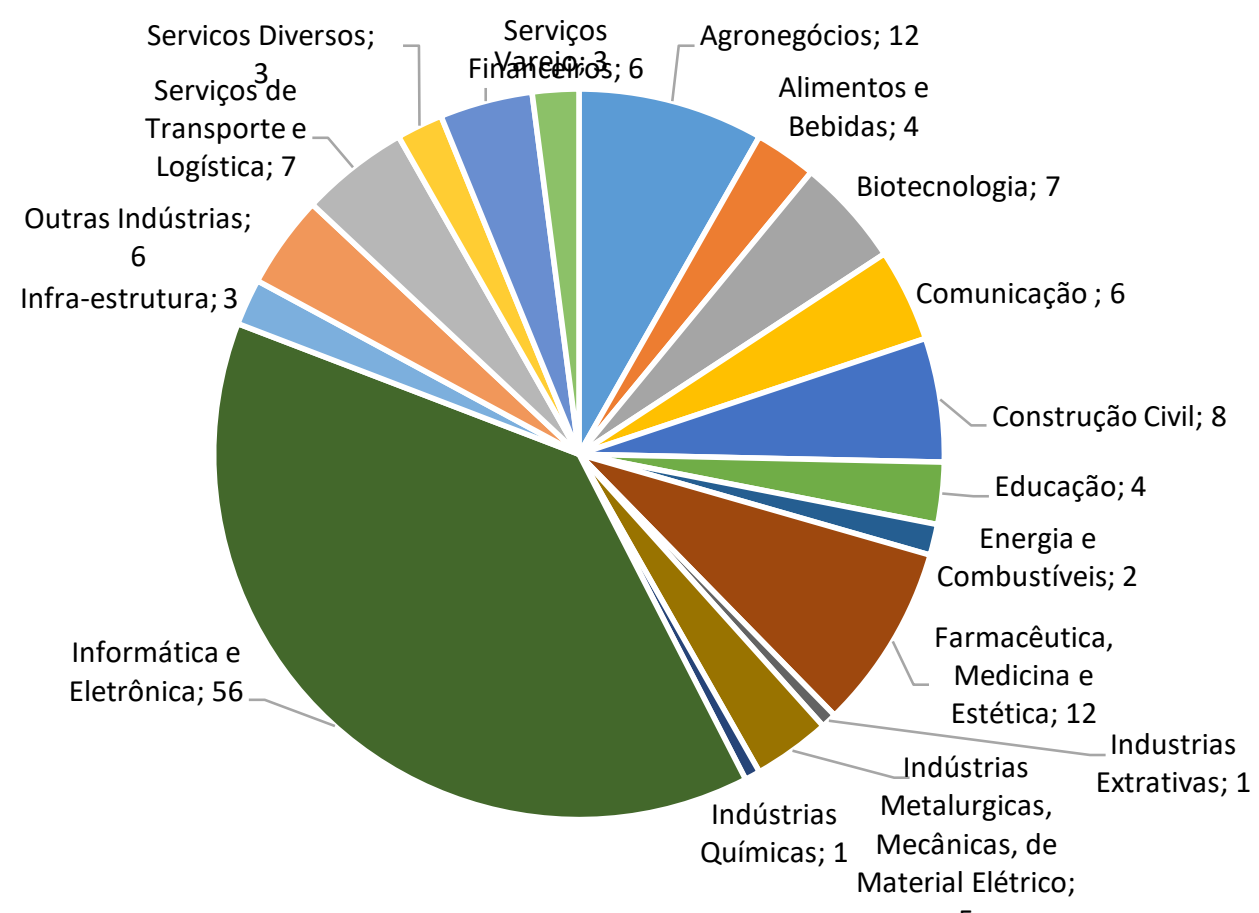

Fonte: Elaborado pela autora a partir de informações disponibilizåadas pela FINEP.

16 Disponível em: < http://www.finep.gov.br/apoio-e-financiamento-externa/programas-e-

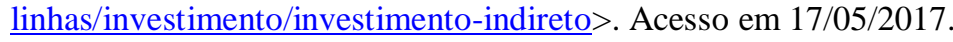


Os dados do CRIATEC E INOVAR revelam que os fundos públicos possuem uma carteira de investimentos mais diversificada, com foco em novas micro ou pequenas empresas emergentes com maior conteúdo tecnológico, do que aqueles discutidos na seção 4. Cabe frisar que mesmo dentro dos programas públicos, há uma certa preferência por empresas com trajetórias tecnológicas bem definidas como, por exemplo, aquelas observadas no segmento de TIC. A exceção talvez caiba ao CRIATEC. Dado o perfil das empresas investidas, os fundos do CRIATEC parecem mais propensos a investir em tecnologias mais inovadoras empreendidas por negócios ainda insipientes.

\section{Síntese e Conclusões}

Este artigo teve como objetivo explorar o papel e as contribuições da indústria de VC para o financiamento da inovação tecnológica no Brasil. O ponto de partida da argumentação foi a análise da trajetória institucional da operação de VC no país. Essa análise explicitou que a indústria de VC brasileira começou a ser delineada em conjunto com as operações de PE na década de 1970. Naquela época, o governo federal e a inciativa privada realizaram uma série de investimentos na aquisição de ações - ou de outros valores mobiliários - de empresas com alto potencial de rentabilidade e crescimento. Em particular, o governo federal enxergou nos investimentos com participação acionária a possibilidade de financiar a produção nacional de bens de capital, insumos e energia.

De lá para cá, a indústria de VC brasileira se beneficiou de melhorias nos ambientes macroeconômico, legal, fiscal e regulatório e da implantação de programas públicos de financiamento à inovação. A despeito das melhorias ambientais observadas, esses avanços não foram capazes de impulsionar o desenvolvimento de uma indústria de $\mathrm{VC}$ vibrante. Isso fica claro ao se analisar o perfil de 52 investimentos feitos por 13 organizações de VC entre 1999 e 2013. Os resultados apresentados no artigo apontam que essas organizações tendem a direcionar boa parte de seus investimentos para empresas que desenvolvem produtos e/ou serviços com trajetórias tecnológicas bem definidas como, por exemplo, o serviço de comércio eletrônico. A análise também revelou que muitas organizações de VC seguem a estratégia de investir em empresas que "tropicalizam" produtos e/ou serviços já comercializados em outros países.

$\mathrm{Na}$ sequência da argumentação, buscou-se o entendimento das contribuições dos programas públicos de VC no Brasil. Os dois programas analisados foram o CRIATEC e o INOVAR. Em linhas gerais, o artigo revelou que o grande risco de financiar empreendimentos mais inovadores e com mercados pouco desenvolvidos tem sido tomado pelo VC público. Com esses dois programas, o Estado vem criando fundos que privilegiam setores que as iniciativas privadas de VC por si só não investiriam ou investem pouco como, por exemplo, energia limpa e nanotecnologia. O setor público também é responsável por criar fundos dedicados ao capital semente, ou seja, para o financiamento dos esforços de P\&D de empresas nascentes. Além de ter uma disposição maior para o risco, o setor público também se destaca por financiar grande parte dos fundos gerenciados pelo setor privado. Esse protagonismo tem levado o Estado a assumir no mínimo três papéis controversos na indústria de VC: articulador político, financiador de fundo e cotista de empresa investida.

Diante do exposto, a conclusão que se chega é que a indústria de VC tem um papel muito pequeno no financiamento do desenvolvimento tecnológico brasileiro. Atualmente esse papel se concentra no financiamento de empresas que desenvolvem produtos/serviços não tão sofisticados no setor de TIC. Quanto à sua localização institucional, percebe-se que a indústria de VC é fortemente dependente da ação do Estado. Sem investimentos públicos, dificilmente as organizações de VC alocariam capital em empreendimentos mais inovadores com produtos e mercados pouco desenvolvidos. Percebe-se, portanto, que a atual indústria de $\mathrm{VC}$ possui um papel secundário no financiamento do desenvolvimento tecnológico que o Brasil precisa para realizar o tão almejado catching up. 
Por fim, cabe sugerir aqui novas agendas de estudos que possam complementar as percepções sobre as possíveis contribuições da indústria de $\mathrm{VC}$ para o processo de catching up que o país tanto almeja. A primeira é entender como o atual estágio de desenvolvimento do sistema de inovação brasileiro afeta a oferta de empresas para indústria de VC. A segunda é explorar como o atual estágio de desenvolvimento do mercado acionário brasileiro influência o dinamismo e lucratividade da indústria de VC. Buscar esse entendimento é necessário para compreender quais são as perspectivas, as limitações e os desafios para que a indústria de VC possa contribuir mais efetivamente com a modernização da indústria brasileira.

\section{Referências e citações}

ABDI - AGÊNCIA BRASILEIRA DE DESENVOLVIMENTO INDUSTRIAL. A indústria de private equity e venture capital: $2^{\circ}$ censo brasileiro. Brasília, 2011. Disponível em:< http://www.abdi.com.br/Estudo/Private_Equity_e_Venture_Censo.pdf>. Acesso em 12/09/2016.

ABVCAP - ASSOCIAÇÃO BRASILEIRA DE PRIVATE EQUITY E VENTURE CAPITAL. [Base de dados]. Disponível em: <http://www.abvcap.com.br>. Acesso em 12/09/2016.

BNDES - BANCO NACIONAL DE DESENVOLVIMENTO ECONÔMICO. [Fundos da série CRIATEC]. Disponível em: < http://www.bndes.gov.br/SiteBNDES/bndes/bndes_pt/Institucional/Apoio_Financeiro/Programas_e _Fundos/Criatec/> Acesso em 17/05/2017.

BLACK, B.; GILSON, R. Venture capital and the structure of capital markets banks vs stock markets. Journal of Financial Economics, v. 47, p. 243-277, 1998.

BMF\&BOVESPA. [Empresas listadas]. Disponível em: <http://www.bmfbovespa.com.br/ciaslistadas/empresas-listadas/BuscaEmpresaListada.aspx?Idioma=pt-br>. Acesso em: 17/05/2017.

BRASILPAR [Informações empresa]. Disponível em: 〈http://www.brasilpar.com.br>. Acesso em $17 / 05 / 2017$.

CARVALHO, A. G.; RIBEIRO, L. L.; FURTADO, C. V. A indústria de private equity e venture capital: primeiro censo brasileiro. São Paulo: Saraiva, 2006.

CHESNAIS, François; SAUVIAT, Catherine. O financiamento da inovação no regime global de acumulação dominado pelo capital financeiro. In LASTRES, Helena Maria M.; CASSIOLATO, José E.; ARROIO, Ana. Conhecimento, sistemas de inovação e desenvolvimento, Rio de Janeiro: Editora UFRJ, Contraponto, 2005. cap. 5, p. 161-219.

CHESNAIS, F. The special position of the United States in the finance- led regime: how exportable is the US venture capital industry. In: CORIAT, Benjamin; SCHMÉDER, Geneviève; PETIT, Pascal. The hardship of nations: exploring the paths of modern capitalism. Edward Elga, 2006. cap. 2, p. 3767.

CVM - COMISSÃO DE VALORES MOBILIÁRIOS. Instrução CVM $N^{o} 209$ de 25 de março de 1994. Disponível em: < http://www.cvm.gov.br/legislacao/inst/inst209.html>. Acesso em $17 / 05 / 2017$. 
2003. Disponível em: <http://www.cvm.gov.br/legislacao/inst/inst391.html>. Acesso em 17/05/2017.

Instrução CVM $N^{o} 391$, de 30 de agosto de 2016. Disponível em: <http://www.cvm.gov.br/legislacao/inst/inst578.html>. Acesso em $17 / 05 / 2017$.

COUTINHO, L. Coréia do Sul e Brasil: paralelos, sucessos e desastres. In: FIORI, José Luís. Estados e moedas no desenvolvimento das nações. Petrópolis, RJ: Vozes. 3 ed, 1999. p. 351-378.

CRIATEC. [Carteira de Investimentos]. Disponível em:< http://www.fundocriatec.com.br/ptBR/carteira-de-investimentos\#all>. Acesso em 17/05/2017.

CRIATEC II. [Portfolio]. Disponível em: $<$ http://www.criatec2.com.br/portfolio/>. Acesso em $17 / 05 / 2017$.

CRP. [Informações empresa]. Disponível em: <http://www.crp.com.br>. Acesso em 17/05/2017.

ETZKOWITZ, H. The renewal of venture capital: Toward a counter-cyclical model. Technology Analysis and Strategic Management, v. 17, n.1, p. 73-87, 2005.

FINEP - FINANCIADORA DE ESTUDOS E PROJETOS. Projeto Inovar: ações e resultados. 2001. Disponível em: < http://www.finep.gov.br/images/afinep/transparencia/relatorios/relatorio_inovar/relatorio_inovar.pdf>. Acesso em 17/05/2017.

. [O que é o programa Inova]. Disponível em: < http://www.finep.gov.br/apoio-e-financiamento-externa/programas-e-linhas/programasinova/o-que-e-o-programa-inova>. Acesso em 17/05/2017.

http://www.finep.gov.br/apoio-e-financiamento-externa/programas-e-

linhas/investimento/investimento-indireto>. Acesso em 17/05/2017.

FREITAS, R.; PASSONI, P. Brazilian capital markets and private equity: a new reality or just a fad? Havard Business School, p. 1-35, 2006.

GOMPERS, P.; LERNER, J. The venture capital cycle. Cambridge, Mass.: The MIT Press, 1999.

The money of invention: how venture capital creates new wealth. Boston: Harvard Business School Press, 2001.

GORGULHO, L. O capital de risco como alternativa de financiamento às pequenas e médias empresas de base tecnológica: o caso do contec/BNDES. 1996, 181 f. Dissertação de Mestrado em Economia, Instituto de Economia Industrial, Universidade Federal do Rio de Janeiro, Rio de Janeiro.

INSEED. [O Criatec]. Disponível em: < http://www.inseedinvestimentos.com.br/criatec3/>. Acesso em 17/05/2017. 
KAPLAN, Steven; STROMBERG, Per. Leveraged buyouts and private equity. Journal of Economic Perspectives, v. 22, n.4, p. 1-27, 2008.

KPMG. Consolidação de dados da indústria de private equity e venture capital no Brasil 2011/2012, 2013. Disponível em http://www.abvcap.com.br/Download/Estudos/2325.pdf. Acesso em 17/05/17.

LEAMON, A.; LERNER, J. Creating a venture ecosystem in Brazil: FINEP's Inovar project [Working paper]. Harvard Business School, 2012.

LEEDS, R.; SUNDERLAND, J. Private equity investing in emerging markets. Journal of Applied Corporate Finance, v.15, n. 4, p. 111-119, 2003.

LEONEL, S. G. Mitos e verdades sobre a indústria de venture capital. 2014, $186 \mathrm{f}$. Tese de Doutorado em Economia, Centro de Desenvolvimento e Planejamento Regional, Universidade Federal de Minas Gerais, Belo Horizonte.

MIT - MASSACHUSETTS INSTITUTE OF TECHNOLOGY. Brazil VC ecosystem study. MIT Sloan Management, $2013 . \quad$ Disponível em http://mitbrazilventurecapitalstudy.files.wordpress.com/2013/03/mit-brazil-vc-study-2012-

2013.pdf> Acesso em 17/05/2017.

MELO, L. M. Financiamento à inovação no brasil: análise da aplicação dos recursos do Fundo Nacional de Desenvolvimento Científico e Tecnológico (FNDCT) e da Financiadora de Estudos e Projetos (FINEP) de 1967 a 2006. Revista Brasileira de Inovação, v. 8, n. 1, p.87-120, 2009

METRICK, A.; YASUDA, A. Venture capital and the finance of innovation. John Wiley \& Sons, New York, 2ed, 2010.

MULCAHY, Diane. Myths about venture capitalists. Harvard Review, n. 81, p. 81-83, 2013.

NAJBERG, S. Transformação do sistema BNDES em financiador do setor privado nacional. Brasília: $\quad$ BNDES, $1989 . \quad$ Disponível em: < http://www.bndes.gov.br/SiteBNDES/export/sites/default/bndes_pt/Galerias/Arquivos/conheciment o/livro_ideias/livro-13.pdf>. Acesso em 17/05/2017.

NVCA - NATIONAL VENTURE CAPITAL ASSOCIATION. Yearbook 2016. New York: Thomson Reutes, 2016.

PAVANI, C. O capital de risco no brasil: conceito, evolução, perspectiva. Rio de Janeiro: E-papers, 2003.

PREQIN. [Base de dados]. Disponível em: < www.preqin.com>. Acesso em 17/05/2017.

RAMALHO, C. Fostering innovation and entrepreneurship in Brazil through private equity and venture capital public policies [Online] Disponivel: SSRN: http://ssrn.com/abstract=1607223, 2010.

RIBEIRO, L. L. O modelo brasileiro de private equity e venture capital. 2005, 139 f. Dissertação de Mestrado em Administração, Departamento de Administração da Faculdade de Economia, Administração e Contabilidade, Universidade de São Paulo, São Paulo. 
RODRÍGUEZ, O. O estruturalismo latino-americano. Rio de Janeiro: Civilização Brasileira, 2009.

SAHLMAN, W. A. The structure and governance of venture capital organizations. Journal of Financial Economics, n 27, p. 473-524, 1990.

SOUZA NETO, J. A.; STAL, E. Financiamento de risco para a inovação tecnológica na empresa. Revista de Administração, v. 26, n. 4, p. 34-47, 1991.

TAVARES, M. C. Império, território e dinheiro. In: FIORI, José Luís. Estados e moedas no desenvolvimento das nações. Petrópolis, RJ: Ed. Vozes, 1999. p. 449-489.

THE ECONOMIST. VC clone home. Disponível em: < http://www.economist.com/node/21556269>. Acesso em 17/05/2017.

WOOD, Geoffrey; WRIGHT, Mike. Private equity: a review and synthesis. International Journal of Management Reviews, v. 11, n.4, p. 361-380, 2009.

ZIDER, B. How venture capital works. Havard Business Review. Nov-Dez, p. 131-139, 1998. 